\title{
Honokiol inhibits bladder cancer cell invasion through repressing SRC-3 expression and epithelial-mesenchymal transition
}

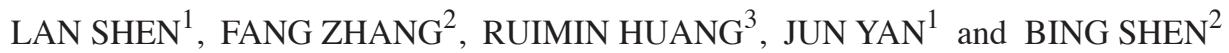 \\ ${ }^{1}$ State Key Laboratory of Pharmaceutical Biotechnology and MOE Key Laboratory of Model Animals for Disease Study, \\ Model Animal Research Center of Nanjing University, Nanjing, Jiangsu $210061 ;{ }^{2}$ Department of Urology, \\ Shanghai General Hospital, Shanghai Jiaotong University, Shanghai 200080; ${ }^{3}$ State Key Laboratory of Drug Research, \\ Shanghai Institute of Materia Medica, Chinese Academy of Sciences, Shanghai 201203, P.R. China
}

Received April 16, 2016; Accepted June 15, 2017

DOI: $10.3892 / 01.2017 .6665$

\begin{abstract}
Urinary bladder cancer (UBC) is one of the most common urological cancer types. Muscle invasive bladder cancer possesses high propensity for metastasis with poor prognosis. Honokiol is a lignan isolated from Magnolia officinalis with high bioavailability and potent anticancer effects. The results of the present study demonstrated that honokiol significantly inhibited UBC cell migration and invasion in a dose-dependent manner compared with the vehicle-treated control group. In addition, honokiol treatment suppressed epithelial-mesenchymal transition by induction of E-cadherin and repression of $\mathrm{N}$-cadherin. Honokiol was capable of significantly downregulating the expression of cell invasion-associated genes, steroid receptor coactivator-3 (SRC-3), matrix metalloproteinase (MMP)-2 and Twist1. Notably, the inhibition of UBC cell invasion by honokiol was reversed by reintroduction of oncoprotein SRC-3 expression, with the restoration of MMP-2 and Twist1, and reduction of E-cadherin expression. Furthermore, the results of the luciferase assay confirmed that SRC-3 could regulate Twist1 promoter activity. Taken together, the results of the present study suggest that
\end{abstract}

Correspondence to: Dr Jun Yan, State Key Laboratory of Pharmaceutical Biotechnology and MOE Key Laboratory of Model Animals for Disease Study, Model Animal Research Center of Nanjing University, 12 Xuefu Road, Nanjing, Jiangsu 210061, P.R. China

E-mail: yanjun@nju.edu.cn

Dr Bing Shen, Department of Urology, Shanghai General Hospital, Shanghai Jiaotong University, 100 Haining Road, Shanghai 200080, P.R. China

E-mail: shenbingyishi@163.com

Abbreviations: UBC, urinary bladder cancer; MMP, matrix metalloproteinase; EMT, epithelial-mesenchymal transition; SRC-3, steroid receptor coactivator-3

Key words: honokiol, bladder cancer, cell invasion, steroid receptor coactivator-3, epithelial-mesenchymal transition, Twist1 honokiol is a promising agent against UBC cell invasion via downregulation of SRC-3 and its target genes.

\section{Introduction}

Urinary bladder cancer (UBC) is one of the most common types of malignant tumor in the United States, with an estimated 58,950 new cases and 11,820 UBC-associated mortalities in 2016 (1). Data between 2005 and 2011 in USA revealed that the 5 -year survival rate for localized UBC was $\sim 70 \%$, whereas the rate for patients with $\mathrm{UBC}$ with distant lesions was $~ 5 \%$ (1). In China, bladder cancer prevalence ranks the 9th and the 2nd positions for the entire population, and people $>65$ years, respectively (2). However, current treatments, including chemotherapy and radiotherapy possess limited effects on muscle invasive bladder cancer (>stage 2 ). Therefore, studies investigating the underlying molecular mechanisms of UBC development and the development of efficacious therapeutic reagents for $\mathrm{UBC}$, particularly for patients with invasive cancer are warranted.

Steroid receptor coactivator-3 (SRC-3) and alias amplification in breast cancer 1 belong to the p160 steroid receptor coactivator family (3). Amplification and/or overexpression of SRC-3 have been implicated in steroid-targeted tissues, including in breast and prostate cancer (4-6), and in non-steroid-targeted tissues, including lung and bladder cancer (7-10). Accumulating evidence indicates that SRC-3 can activate steroid and non-steroid receptors. For example, SRC-3 serves as a co-activator for transcription factors ETS variant 4 (PEA3) and JunB proto-oncogene AP-1 transcription factor subunit, which leads to the upregulation of matrix metalloproteinase (MMP)-2, and -13 in androgen receptor-null PC3 prostate cancer cells (11). Furthermore, SRC-3 facilitates E2F transcription factor 1 (E2F1) to promote the proliferation of breast cancer cells (12). Previous studies, including our previous study, have demonstrated that SRC-3 cooperates with hypoxia-inducible factor $1-\alpha$ and $\mathrm{E} 2 \mathrm{~F} 1$, thus promoting the survival and proliferation of UBC cells $(9,13)$. However, whether SRC-3 serves a role in cell migration and invasion of UBC remains unclear.

Honokiol is the major active component derived from the stem and bark of the plant Magnolia officinalis, a 
traditional Chinese medicine. As one of the major lignans with high bioavailability, honokiol exhibits multiple biological properties, including muscle relaxant, neuroprotective, anti-inflammatory and anticancer effects (14-19). However, whether honokiol exhibits an effect UBC cell migration and invasion remains unclear. The present study demonstrated that honokiol inhibited UBC cell invasion by repressing the process of epithelial-mesenchymal transition (EMT). It was further revealed that honokiol downregulated Twist1 (an EMT-associated transcription factor) and MMP-2 (an enzyme associated with cell invasion) via suppressing SRC-3 expression. However, overexpression of SRC-3 reversed the honokiol-mediated inhibition of UBC cell migration and invasion.

\section{Materials and methods}

Human bladder cancer cell line and reagents. The human bladder cancer J82 cell line was obtained from the Type Culture Collection of the Chinese Academy of Sciences Cell Bank (Shanghai, China) and maintained in RPMI-1640 medium (cat no. 31800-022; Gibco; Thermo Fisher Scientific, Inc., Waltham, MA, USA) supplemented with $10 \%$ fetal bovine serum (FBS-12A; Capricorn Scientific $\mathrm{GmbH}$, Ebsdorfergrund, Germany). Cells were cultured at $37^{\circ} \mathrm{C}$ in a humidified atmosphere with $5 \% \mathrm{CO}_{2}$. HonoPure $(98 \%$ honokiol; EcoNugenics, Santa Rosa, CA, USA) was dissolved in dimethyl sulfoxide and further diluted with RPMI-1640 medium immediately prior to use. For each protocol, cells treated with DMSO vehicle were used as the negative control.

Luciferase assay. Luciferase assays were performed using a Dual-Luciferase Reporter Assay System kit (cat no. 1910; Promega Corporation, Madison, WI, USA) according to the manufacturer's protocol. The Twistl gene promoter was inserted into the pGL3-basic vector (Promega Corporation) to generate the $100 \mathrm{ng}$ Twist1 reporter plasmid (Twist1-Luc) (20). Subsequent to the J82 cells reaching $60 \%$ confluency in 24 -well plates, Twist1-Luc plasmid was co-transfected into cells with 100 ng SRC-3 expression plasmid, which was constructed by the insertion of the open reading frame of the human SRC-3 gene into pCMV10-3xFLAG (Sigma-Aldrich; Merck KGaA, Darmstadt, Germany) (9). Honokiol at various concentrations (0-4.8 $\mu \mathrm{g} / \mathrm{ml})$ were added 1 day following plasmid transfection. After $24 \mathrm{~h}$ of incubation at $37^{\circ} \mathrm{C}$, the cells were lysed for use in the luciferase assay. A total of $100 \mu 1$ 1X Passive Lysis Buffer (Promega Corporation) were used to lyse the cells, and then they were tested for luciferase activity according to the protocol. Renilla luciferase activity was used for normalization.

RNA isolation and reverse transcription-quantitative PCR (RT-qPCR). Total RNA was isolated using TRIzol reagent (cat no. 15596018; Invitrogen; Thermo Fisher Scientific, Inc.). RT was conducted with random primers in the Takara PrimeScript $^{\mathrm{TM}}$ RT reagent system (Takara Biotechnology Co., Ltd., Dalian, China) according to the manufacturer's protocol. The expression levels of genes were measured using SYBR-Green-based qPCR (Takara Biotechnology Co., Ltd.). The thermocycler protocol was $95^{\circ} \mathrm{C}$ for $10 \mathrm{sec}$, then $95^{\circ} \mathrm{C}$ for $5 \mathrm{sec}, 60^{\circ} \mathrm{C}$ for $31 \mathrm{sec}$ for 40 cycles from step 2 to step 3 . The formula $2^{-\Delta \Delta \mathrm{Cq}}(\mathrm{Cq}$ cycle threshold) was used to determine the expression levels of target genes normalized by $\beta$-actin (21). qPCR was performed in triplicate for each sample. The primer sequences used were as follows: SRC-3 forward, 5'-GGGACTAAGCAACAGGTGTTT-3' and reverse, 5'-TTTGGCCCACCCATACTTGAG-3'; MMP-2 forward, 5'-CCGTCGCCCATCATCAAGTT-3' and reverse, 5'-CTGTCTGGGGCAGTCCAAAG-3'; Twist1 forward, 5'-TGGAGGACCTGGTAGAGGAA-3' and reverse, 5'-GTC CGCAGTCTTACGAGGAG-3'; $\beta$-actin forward, 5'-CAT GTACGTTGCTATCCAGGC-3' and reverse, 5'-CTCCTT AATGTCACGCACGA-3'.

Western blotting. Cells were lysed in RIPA buffer containing a phosphatase inhibitor cocktail I (Sigma-Aldrich; Merck $\mathrm{KGaA}$ ) and a protease inhibitor cocktail mini-tablet (Roche Diagnostics, Indianapolis, IN, USA). Subsequently, Bradford regent was used to determine protein concentration, and $20 \mu \mathrm{g}$ protein/lane were separated using 10\% SDS-PAGE and transferred onto a polyvinylidene difluoride membrane. The membrane was blocked by $5 \%$ non-fat milk at room temperature for $1 \mathrm{~h}$. Primary antibodies directed against E-cadherin (cat no. BS1098; 1:1,000; Bioworld Technology, Inc., St. Louis Park, MN, USA), N-cadherin (cat no. 22018-1-AP; 1:1,000; ProteinTech Group, Inc., Chicago, IL, USA), SRC-3 (cat no. 611104; 1:1,000; BD Biosciences, San Jose, CA, USA), MMP-2 (cat no. 29090; 1:1,000), Twist1 (cat no. 21642; 1:1,000) (both from Signalway Antibody, College Park, MA, USA), and $\beta$-actin (cat no. 05-0079; 1:1,000; AbMax Biotechnology Co., Ltd., Beijing, China) were incubated with the membrane overnight at $4^{\circ} \mathrm{C}$. Subsequent to washing three times with $1 \mathrm{X}$ PBST [1 ml Tween-20 diluted in 1,000 ml 1X PBS (140 mM $\left.\left.\mathrm{NaCl}, 2.7 \mathrm{mM} \mathrm{KCl}, 1.8 \mathrm{mM} \mathrm{KH}{ }_{2} \mathrm{PO} 4,10 \mathrm{mM} \mathrm{Na}{ }_{2} \mathrm{HPO}_{4}\right)\right]$, corresponding mouse and rabbit secondary antibodies conjugated with horseradish peroxidase (cat nos. 7076 and 7074; Cell Signaling Technology, Inc., Danvers, MA, USA) were then used at room temperature for $2 \mathrm{~h}$. The western blots were visualized using enhanced chemiluminescence reagents (cat no. 180-501; Tanon Science and Technology Co., Ltd., Shanghai, China).

Wound healing assay. Cells were seeded at a density of $5 \times 10^{5}$ cells/well into $35-\mathrm{mm}$ dishes and treated with $0,2.4$ or $4.8 \mu \mathrm{g} / \mathrm{ml}$ honokiol. After $24 \mathrm{~h}$, a wound scratch was made with a $100 \mu$ l pipette tip on cell monolayer and images were captured after $24 \mathrm{~h}$ to estimate the area occupied by migratory cells. Cells were maintained at $37^{\circ} \mathrm{C}$ throughout the protocol.

Transwell invasion assay. Following treatment with different concentrations of honokiol, $1 \times 10^{5} \mathrm{~J} 82$ cells were diluted in $500 \mu \mathrm{l}$ serum-free RPMI-1640 medium and inoculated in the upper Transwell chamber coated with growth factor-reduced Matrigel. RPMI-1640 medium containing 10\% FBS was added to the lower chamber as a chemoattractant. Following $16 \mathrm{~h}$, cells on upper surface of the membrane were removed using a Q-tip, and invaded cells were fixed with $4 \%$ formaldehyde for $10 \mathrm{~min}$ at room temperature followed by $0.5 \%$ crystal violet staining (Sigma-Aldrich; Merck KGaA) for another $10 \mathrm{~min}$ at room temperature. The numbers of invaded cells were counted 


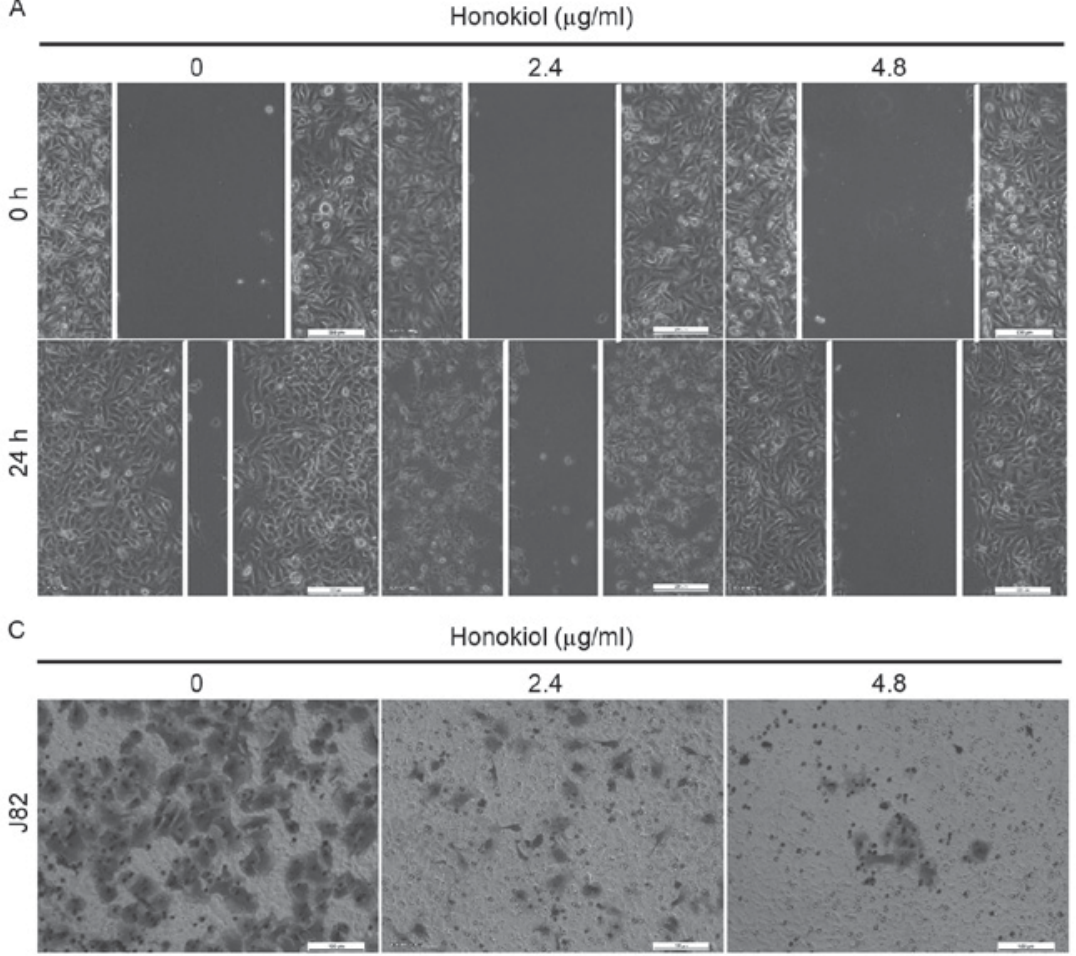

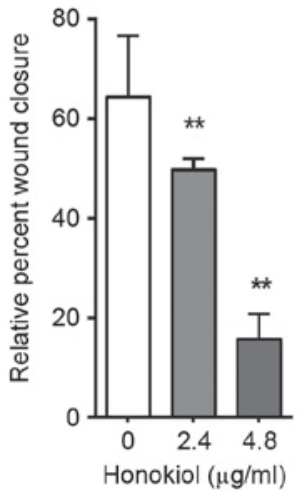

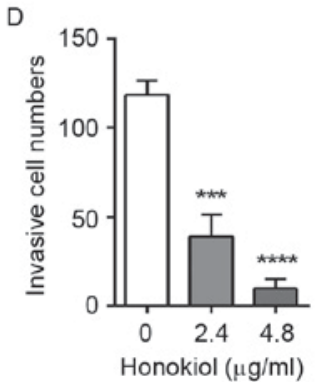

Figure 1. Honokiol inhibits UBC cell migration and invasion. (A) Representative image and (B) quantification of the wound healing assay results, which revealed that honokiol $(2.4$ and $4.8 \mu \mathrm{g} / \mathrm{ml})$ significantly inhibited the migration capacity of J82 cells following $24 \mathrm{~h}$ of treatment in a dose-dependent manner. Scale bar, $200 \mu \mathrm{m}$. (C) Representative image and (D) quantification of the Transwell assay results demonstrated that honokiol (2.4 and $4.8 \mu \mathrm{g} / \mathrm{ml})$ repressed J82 cells invasion capacity following $16 \mathrm{~h}$ of treatment in a dose-dependent manner. Scale bar, $100 \mu \mathrm{m} .{ }^{* * *} \mathrm{P}<0.01,{ }^{* * * *} \mathrm{P}<0.001,{ }^{* * * * *} \mathrm{P}<0.0001$. Data are represented as the mean \pm standard deviation following experiments performed in triplicate.

in five randomly chosen fields under a light microscope at $\mathrm{x} 20$ magnification.

Cell viability assay. J82 cells were seeded into 96-well plates at a density of $1 \times 10^{4}$ cells/well. Honokiol at various concentrations $(0-4.8 \mu \mathrm{g} / \mathrm{ml})$ were added 1 day after cell inoculation. Following treatment with honokiol for $16 \mathrm{~h}$, cells were washed with PBS and $5 \mathrm{mg} / \mathrm{ml} \mathrm{MTT}$ was added for $3 \mathrm{~h}$ at $37^{\circ} \mathrm{C}$. Subsequently, $100 \mu \mathrm{l} \mathrm{DMSO} /$ well was loaded to dissolve the formazan crystals. Plates were incubated at $37^{\circ} \mathrm{C}$ for $15 \mathrm{~min}$. Absorbance at $490 \mathrm{~nm}$ was examined using a microplate reader (BioTek Instruments, Inc., Winooski, VT, USA) and absorbance at $680 \mathrm{~nm}$ was used as reference.

Immunofluorescence staining. Cells growing on the coverslips in 24-well plates were fixed by $4 \%$ paraformaldehyde for 15 min and washed with PBS three times. After blocking with $5 \%$ BSA in PBS for $60 \mathrm{~min}$, the coverslips were incubated in the primary antibodies against E-cadherin (Bioworld Technology) and N-cadherin (ProteinTech Group, Inc.) were used overnight at $4^{\circ} \mathrm{C}$. Fluorescein-conjugated secondary antibodies were applied, followed by DAPI counterstaining.

Statistical analysis. Each experiment was repeated three times. Data are represented as the mean \pm standard deviation following experiments performed in triplicate. The significant difference between control and experimental groups was analyzed using the Student's t-test. $\mathrm{P}<0.05$ was considered to indicate a statistically significant difference. All of the statistical analyses were performed with Graphpad Prism 5 software (GraphPad Software, Inc., La Jolla, CA, USA).

\section{Results}

Honokiol inhibits UBC cell migration and invasion. Patients with bladder cancer with metastatic lesions have poor prognosis. Thus, an investigation into whether honokiol, an anticancer traditional medicine, has any effects on bladder cancer cell migration and invasion was performed. The highly metastatic human bladder cancer J82 cell line was chosen for the present study. J82 cells were treated with different concentrations of honokiol $(0,2.4$ and $4.8 \mu \mathrm{g} / \mathrm{ml})$. The results from the wound healing assay demonstrated that honokiol was capable of inhibiting the migratory capacity of J82 cells in a dose-dependent manner (Fig. 1A). Following $24 \mathrm{~h}$ treatment with honokiol at 2.4 and $4.8 \mu \mathrm{g} / \mathrm{ml}$, the wound closures were significantly reduced by 23 , and $75 \%$, respectively, compared with that in the vehicle-treated cell group (Fig. 1B). Invasion capacity of UBC cells was measured using Transwell assays. The cells invading into the lower chambers were significantly decreased upon treatment with honokiol for $16 \mathrm{~h}$ compared with the vehicle-treated control group (Fig. 1C and D). The numbers of the invading cells significantly reduced by 67 and $92 \%$ upon 2.4 , and $4.8 \mu \mathrm{g} / \mathrm{ml}$ honokiol treatment, respectively (Fig. 1D). In order to confirm that the honokiol-induced decrease in migration and invasion ability was not merely due to the 


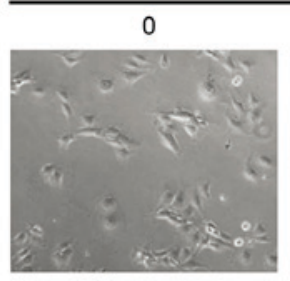

2.4 4.8
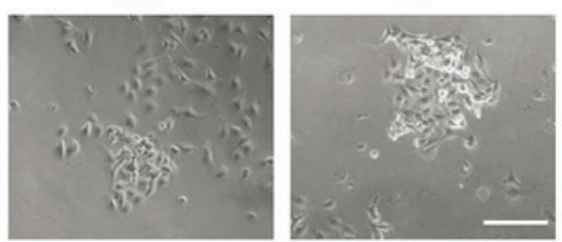

B

E-cadherin DAPI
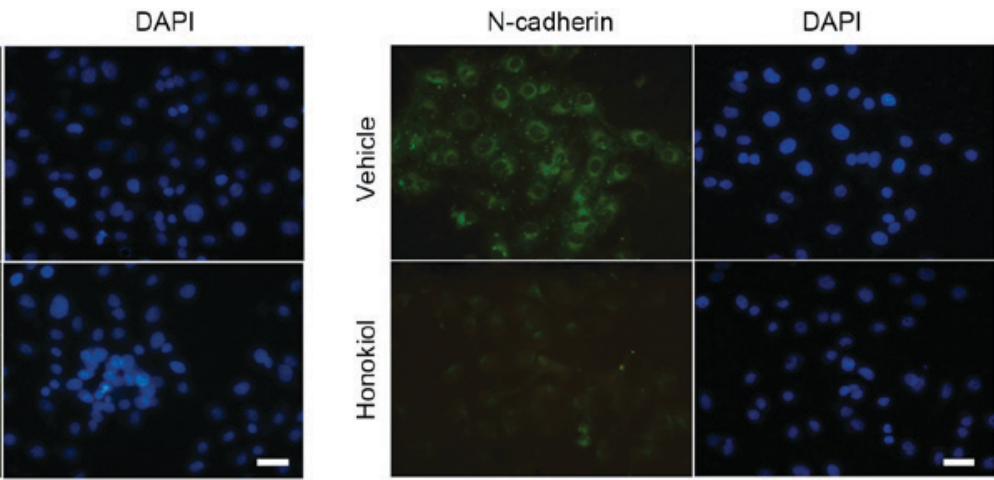

C

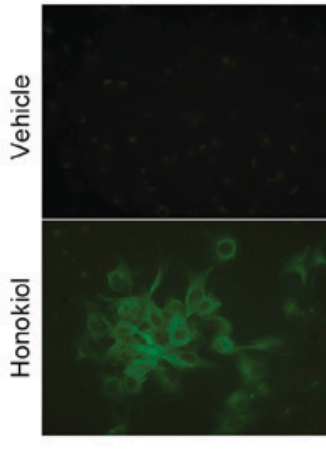

Honokio

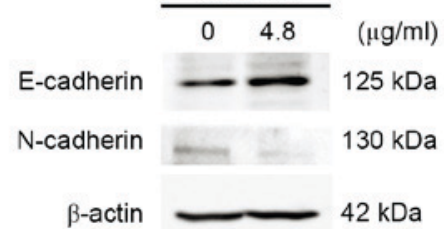

Figure 2. Honokiol suppresses epithelial-mesenchymal transition of bladder cancer cells. (A) Morphologic changes of J82 cells treated with honokiol for $24 \mathrm{~h}$. DMSO was used as vehicle control. Scale bar, $200 \mu \mathrm{m}$. (B) Honokiol treatment increased E-cadherin expression and decreased N-cadherin expression as demonstrated through the immunofluorescence staining assay. Scale bar, $20 \mu \mathrm{m}$. (C) E- and N-cadherin protein expression determined using a western blotting assay. $\beta$-actin was used as a loading control.

decrease of cell number associated with honokiol-induced cell growth arrest, a MTT assay was applied to determine UBC cell viability. J82 cell viability was significantly decreased by 17 and $33 \%$ when treated with 2.4 , and $4.8 \mu \mathrm{g} / \mathrm{ml}$ honokiol for $16 \mathrm{~h}$, respectively, compared with the vehicle control group (data not shown). The inhibition on cell viability observed was less compared with the effects on cell invasion demonstrated using the Transwell assay. These data suggest that honokiol can inhibit UBC cell migration and invasion.

Honokiol suppresses EMT of bladder cancer cells. Since EMT has been implicated in cancer cell invasion, whether EMT could be suppressed by honokiol treatment $(4.8 \mu \mathrm{g} / \mathrm{ml})$ was investigated in J82 cells. Morphological changes, including cell-cell adhesion, were observed upon honokiol treatment (Fig. 2A). Loss of E-cadherin and gain of N-cadherin are considered to be the fundamental events of EMT (22-24). Immunofluorescence staining assays revealed increased expression of E-cadherin and the decreased expression of $\mathrm{N}$-cadherin (Fig. 2B), which were further confirmed by the western blotting assay (Fig. 2C). These results suggest that honokiol suppresses EMT of UBC cells via regulating the expression levels of $\mathrm{E}$ - and $\mathrm{N}$-cadherin.

Honokiol downregulates expression levels of cancer cell invasion-associated genes. To investigate the mechanism underlying the inhibition of UBC cell invasion induced by honokiol, the expression levels of genes associated with cell invasion were determined using RT-qPCR and western blotting assays. The results demonstrated that the expression of SRC-3, MMP-2 and Twist1 was significantly downregulated by honokiol at the mRNA (Fig. 3A) and protein (Fig. 3B) level compared with the vehicle-treated control group. The positive association between SRC-3 and MMP-2 is consistent with the fact that MMP-2 is a direct target of SRC-3 gene (11). Twist1 is a basic helix-loop-helix transcription factor and serves an essential role in cancer metastasis $(20,25)$. To examine whether Twist1 is downregulated by honokiol through inhibition of its promoter activity, J82 cells were transfected with a reporter plasmid, firefly luciferase driven by human Twistl promoter (Twist1-Luc). Following $24 \mathrm{~h}$ of transfection, cells with were treated honokiol for another $24 \mathrm{~h}$. As a result, honokiol $(2.4$ and $4.8 \mu \mathrm{g} / \mathrm{ml}$ ) significantly reduced the luciferase activity of Twist1-reporter in a dose-dependent manner (Fig. 3C). Overall, these data indicate that honokiol represses the expression of genes involved in cancer cell invasion, including SRC-3, MMP-2 and Twist1.

Overexpression of SRC-3 inhibits the effects of honokiol on cell migration and invasion. To further investigate whether honokiol inhibits bladder cancer cells migration and invasion through SRC-3, SRC-3 expression was reintroduced into 


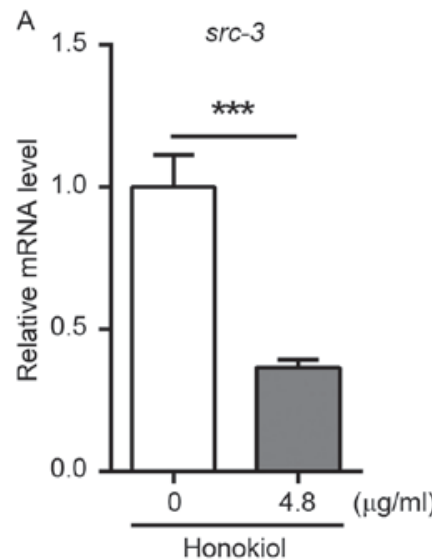

B

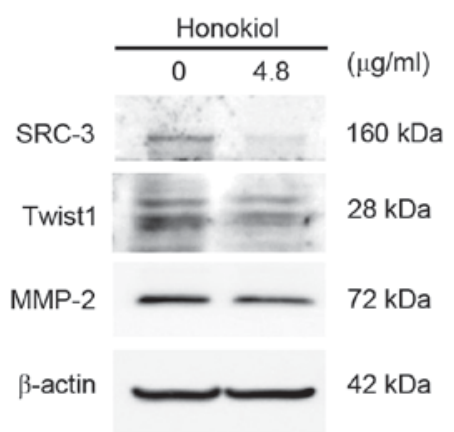

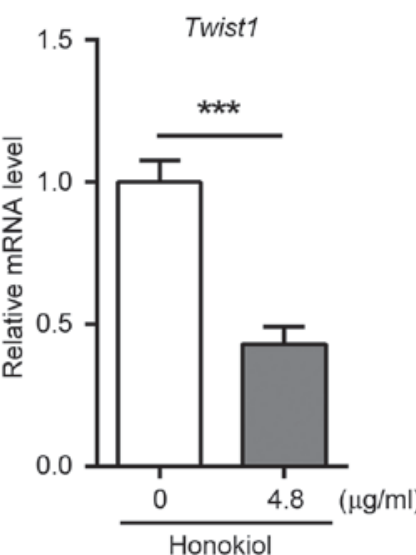
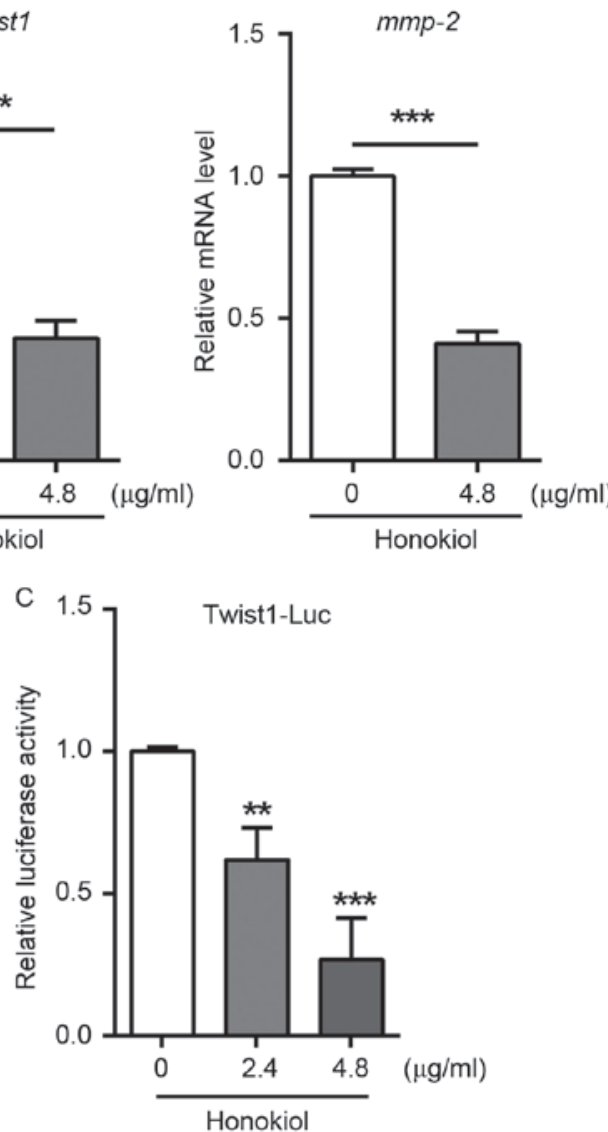

Figure 3. Honokiol reduces genes involved in cancer cell invasion. (A) mRNA and (B) protein expression levels of SRC-3, MMP-2 and Twist1 genes in J82 cells treated with honokiol for $24 \mathrm{~h}$. $\beta$-actin was used as a normalization control. (C) Honokiol significantly suppressed Twist1 gene promoter activity in J82 cells as demonstrated through the luciferase reporter assay. ${ }^{* *} \mathrm{P}<0.01,{ }^{* * * *} \mathrm{P}<0.001$. Data are represented as the mean \pm standard deviation following experiments performed in triplicate. SRC-3, steroid receptor coactivator-3; MMP-2, matrix metalloproteinase 2.

honokiol-treated J82 cells. Empty vector-transfected J82 cells (mock transfectants) were used as a control. In the presence of honokiol $(4.8 \mu \mathrm{g} / \mathrm{ml})$, the ectopic expression of SRC-3 in J82 cells significantly increased the number of invading cells to lower chamber in the Transwell assay compared with that of the mock transfectants (Fig. 4A and B). Furthermore, the ectopic expression of SRC-3 reversed the honokiol-induced changes to E-cadherin, MMP-2 and Twist1 expression (Fig. 4C). Consistently, SRC-3 overexpression almost restored the Twist1-reporter activity under honokiol treatment, suggesting that Twist1 could be a target gene of SRC-3 (Fig. 4D). Taken together, these data suggest that honokiol inhibits UBC cell invasion via repression of EMT and regulation of the expression of cell invasion-associated genes, including SRC-3, MMP-2 and Twist1.

\section{Discussion}

Cell invasion is a highly coordinated cellular process, including secretion of MMPs for degradation of extracellular matrix and morphological changes to facilitate EMT. The cadherin switch from $\mathrm{E}$-cadherin to $\mathrm{N}$-cadherin in EMT has been demonstrated to be essential for bladder cancer-associated mortality $(24,26)$. In the present study, it was demonstrated that a low concentration of honokiol $(4.8 \mu \mathrm{g} / \mathrm{ml})$ was capable of inhibiting UBC cell migration and invasion, which was accompanied with the induction of the epithelial marker E-cadherin, and the reduction of two mesenchymal markers Twist-1 and N-cadherin. Mechanistically, SRC-3, the transcriptional factor coactivator, is indispensable in honokiol-mediated cell invasion inhibition.

SRC-3 is a bona fide oncoprotein in multiple types of solid tumor, including in breast and prostate cancer (5). It was reported that SRC-3 overexpression and amplification occurred in 32.5 , and $7.0 \%$ human UBC specimens $(n=163)$, respectively (10). The expression levels of SRC-3 in patients with UBC have been suggested to be an independent prognostic marker (10). In addition, data from the present study and other studies indicate that overexpression of SRC-3 is essential for UBC cell survival and proliferation $(9,10)$. Therefore, SRC-3 is an important oncoprotein and serves essential roles in UBC development.

Multiple lines of evidence suggest that different mechanisms are used in SRC-3-mediated cancer cell migration and invasion in a cancer-specific manner (10,11,27-29). An inverse correlation between SRC-3 and E-cadherin has been reported in human pancreatic adenocarcinoma, implying that SRC-3 regulates E-cadherin directly or indirectly (27). By co-activating estrogen receptor $\alpha(\mathrm{ER} \alpha)$ in T47D breast cancer cells, SRC-3 also transcriptionally upregulates Snail, which directly represses E-cadherin (28). However, SRC-3 overexpression is not associated with the levels of ER $\alpha$ in UBC tissue samples (10), and urothelial specific ER $\alpha$-knockout enhanced 


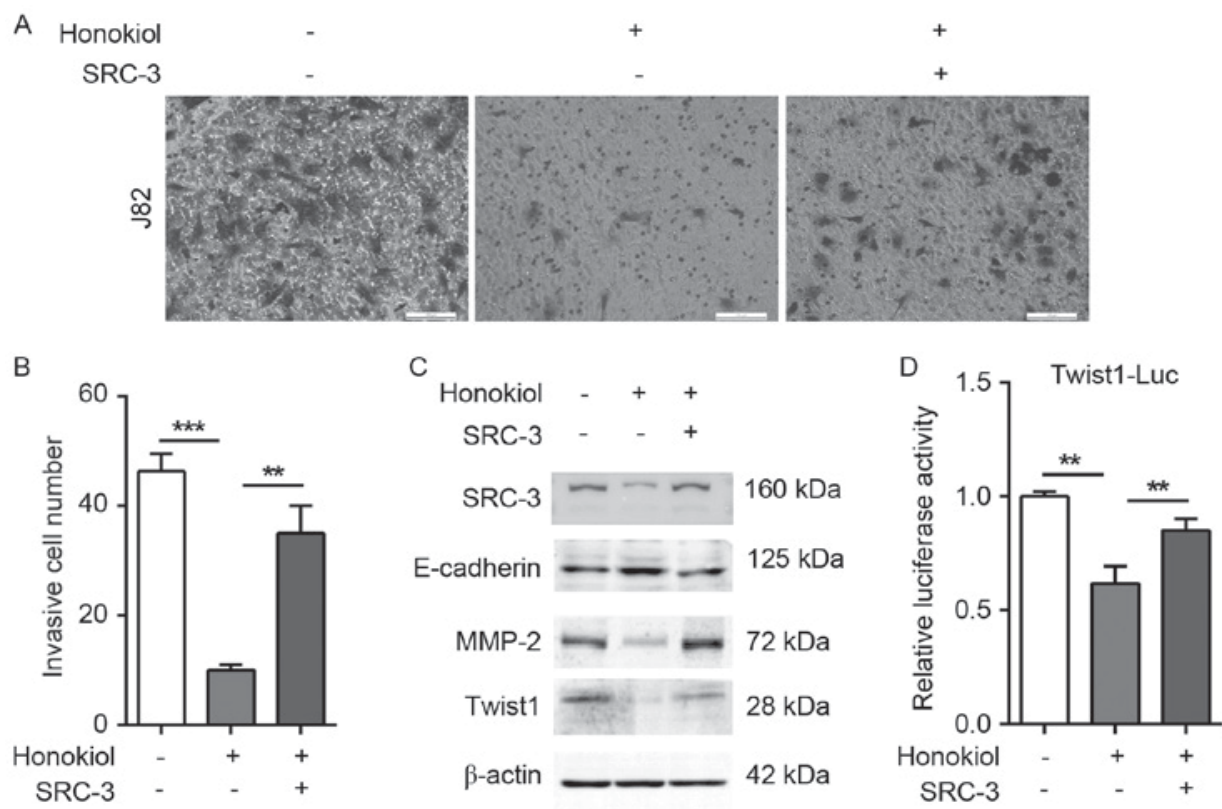

Figure 4. Overexpression of SRC-3 abrogates the effects of honokiol on cell invasion. (A) J82 cells were transfected with SRC-3 expression plasmid (pCMV-3xFLAG-SRC-3) for $24 \mathrm{~h}$, followed by the treatment of honokiol $(4.8 \mu \mathrm{g} / \mathrm{ml}$ ) for another $24 \mathrm{~h}$. The empty vector was used as a negative control. Transwell inserts were stained with crystal violet. Scale bar, $100 \mu \mathrm{m}$. (B) The numbers of invaded cells were counted in five randomized fields under a light microscope and mean values were plotted. (C) Western blotting assay of SRC-3 and invasion/epithelial-mesenchymal transition-associated proteins, MMP-2, E-cadherin, and Twist1. (D) The reduction of Twist1 promoter activity by honokiol treatment was reversed by the forced expression of SRC-3 using luciferase assay. ${ }^{* *} \mathrm{P}<0.01,{ }^{* * *} \mathrm{P}<0.001$. Data are represented as the mean \pm standard deviation following experiments performed in triplicate. SRC-3, steroid receptor coactivator-3; MMP-2, matrix metalloproteinase 2.

carcinogen-induced UBC development, suggesting that ER $\alpha$ behaves as a tumor suppressor in UBC (30). Therefore, SRC-3 is likely to induce EMT through transcription factors other than $\mathrm{ER} \alpha$ in UBC cells. It has been reported that SRC-1, another member of the p160 family, can induce EMT-associated transcription factor Twist1 by co-activating PEA3 (29). In prostate cancer cells, SRC-3 is capable of upregulating MMP-2 by co-activating the PEA3/activator protein-1 complex (11). In the present study, it was demonstrated that SRC-3 is essential for the expression of MMP-2 and Twist1. Notably, the overexpression of SRC-3 in UBC cells reversed honokiol-mediated invasion repression, and upregulated MMP-2 and EMT-associated marker Twistl expression. Therefore, it was hypothesized that SRC-3 enhances UBC cell invasion by co-activating transcriptional factors similar to those activated by PEA3, in order to upregulate Twist1 and MMP-2.

Intensive screening for small molecular inhibitors targeting the oncoprotein SRC-3 is ongoing (31-33). Several potential agents from different chemical libraries, including gossypol, bufalin and verrucarin, have been identified, which all induce the instability of SRC-3 protein (31-33). In the current study, it was demonstrated that honokiol is capable of downregulating the mRNA expression of SRC-3. However, the suppressive effect of honokiol on cancer cell migration and invasion may not be limited to target SRC-3. It has been reported that honokiol targets multiple signaling pathways, including KiSS-1 metastasis-suppressor (KISS1)/KISS1 receptor in renal cell carcinoma (18), signal transducer and activator of transcription 3 signaling in breast cancer (34), epidermal growth factor receptor signaling in head and neck squamous cell carcinoma (35), and the inflammation-associated nuclear factor $\kappa \mathrm{B}$ pathway in other cancer cells $(36,37)$. Penetration through the endothelial cell layer is one of the prerequisite steps in metastasis. Joo et al demonstrated that by reducing the interaction between cancer and endothelial cells, honokiol suppresses EMT and transendothelial invasion of glioblastoma cells via targeting vascular cell adhesion molecule 1 (38). Taken together, these data suggest that honokiol serves a range of inhibitory roles in cancer cell invasion and metastasis, therefore further in vivo studies are warranted to confirm the results presented.

In conclusion, to the best of our knowledge, this is the first study to demonstrate that honokiol inhibits UBC cell migration and invasion via suppression of oncoprotein SRC-3, and two SRC-3 downstream targets, MMP-2 and Twist1. Further clinical trials are required to confirm whether honokiol is a chemotherapeutic agent for patients with UBC, particularly for the muscle invasive subtype.

Dr. Yan once received a research fund from EcoNugenics, which provided honokiol for the present study. However, the current study was not supported using that fund and there was no influence from the EcoNugenics on the study design, data collection and interpretation.

\section{Acknowledgements}

The present study was supported by the National Natural Science Foundation of China (grant nos. 81372168, 81572519 to J.Y. and 81470116 to B.S.), the Natural Science Foundation for Universities in Jiangsu Province of China (grant no. BK20151396 to J.Y.); Wu Jieping Medical Foundation (320.6750.16051 to B.S.); the 'One Hundred Talent Program' of Chinese Academy of Sciences (to R.H.); fund from the State Key Laboratory of Drug Research (grant no. SIMM1705KF-06 
to R.H.) and the Shanghai Natural Science Foundation of China (grant no. 14ZR1433200 to B.S.).

\section{References}

1. Siegel RL, Miller KD and Jemal A: Cancer statistics, 2016. CA Cancer J Clin 66: 7-30, 2016.

2. Zheng R, Zeng H, Zhang S, Chen T and Chen W: National estimates of cancer prevalence in China, 2011. Cancer Lett 370 33-38, 2016.

3. Anzick SL, Kononen J, Walker RL, Azorsa DO, Tanner MM, Guan XY, Sauter G, Kallioniemi OP, Trent JM and Meltzer PS: AIB1, a steroid receptor coactivator amplified in breast and ovarian cancer. Science 277: 965-968, 1997.

4. Zhou HJ, Yan J, Luo W, Ayala G, Lin SH, Erdem H, Ittmann M, Tsai SY and Tsai MJ: SRC-3 is required for prostate cancer cell proliferation and survival. Cancer Res 65: 7976-7983, 2005.

5. Yan J, Tsai SY and Tsai MJ: SRC-3/AIB1: Transcriptional coactivator in oncogenesis. Acta Pharmacol Sin 27: 387-394, 2006.

6. Liao L, Kuang SQ, Yuan Y, Gonzalez SM, O'Malley BW and $\mathrm{Xu} \mathrm{J}$ : Molecular structure and biological function of the cancer-amplified nuclear receptor coactivator SRC-3/AIB1 J Steroid Biochem Mol Biol 83: 3-14, 2002.

7. Cai D, Shames DS, Raso MG, Xie Y, Kim YH, Pollack JR, Girard L, Sullivan JP, Gao B, Peyton M, et al: Steroid receptor coactivator-3 expression in lung cancer and its role in the regulation of cancer cell survival and proliferation. Cancer Res 70: 6477-6485, 2010.

8. Long W, Foulds CE, Qin J, Liu J, Ding C, Lonard DM, Solis LM, Wistuba II, Qin J, Tsai SY, et al: ERK3 signals through SRC-3 coactivator to promote human lung cancer cell invasion. J Clin Invest 122: 1869-1880, 2012

9. Zhao W, Chang C, Cui Y, Zhao X, Yang J, Shen L, Zhou J, Hou Z, Zhang Z, Ye C, et al: Steroid receptor coactivator-3 regulates glucose metabolism in bladder cancer cells through coactivation of hypoxia inducible factor $1 \alpha$. J Biol Chem 289: 11219-11229, 2014.

10. Luo JH, Xie D, Liu MZ, Chen W, Liu YD, Wu GQ, Kung HF, Zeng YX and Guan XY: Protein expression and amplification of AIB1 in human urothelial carcinoma of the bladder and overexpression of AIB1 is a new independent prognostic marker of patient survival. Int J Cancer 122: 2554-2561, 2008.

11. Yan J, Erdem H, Li R, Cai Y, Ayala G, Ittmann M, Yu-Lee LY, Tsai SY and Tsai MJ: Steroid receptor coactivator-3/AIB1 promotes cell migration and invasiveness through focal adhesion turnover and matrix metalloproteinase expression. Cancer Res 68: 5460-5468, 2008

12. Louie MC, Zou JX, Rabinovich A and Chen HW: ACTR/AIB1 functions as an E2F1 coactivator to promote breast cancer cell proliferation and antiestrogen resistance. Mol Cell Biol 24 5157-5171, 2004

13. Tong ZT, Wei JH, Zhang JX, Liang CZ, Liao B, Lu J, Fan S, Chen $\mathrm{ZH}$, Zhang F, Ma HH, et al: AIB1 predicts bladder cancer outcome and promotes bladder cancer cell proliferation through AKT and E2F1. Br J Cancer 108: 1470-1479, 2013.

14. Watanabe $\mathrm{K}$, Watanabe HY, Goto $\mathrm{Y}$, Yamamoto $\mathrm{N}$ and Yoshizaki M: Studies on the active principles of magnolia bark. Centrally acting muscle relaxant activity of magnolol and hōnokiol. Jpn J Pharmacol 25: 605-607, 1975.

15. Arora S, Singh S, Piazza GA, Contreras CM, Panyam J and Singh AP: Honokiol: A novel natural agent for cancer prevention and therapy. Curr Mol Med 12: 1244-1252, 2012

16. Esumi T, Makado G, Zhai H, Shimizu Y, Mitsumoto $Y$ and Fukuyama Y: Efficient synthesis and structure-activity relationship of honokiol, a neurotrophic biphenyl-type neolignan. Bioorg Med Chem Lett 14: 2621-2625, 2004.

17. Zhang Q, Zhao W, Ye C, Zhuang J, Chang C, Li Y, Huang X, Shen L, Li Y, Cui Y, et al: Honokiol inhibits bladder tumor growth by suppressing EZH2/miR-143 axis. Oncotarget 6: 37335-37348, 2015.

18. Cheng S, Castillo V, Eliaz I and Sliva D: Honokiol suppresses metastasis of renal cell carcinoma by targeting KISS1/KISS1R signaling. Int J Oncol 46: 2293-2298, 2015.

19. Jeong JJ, Lee JH, Chang KC and Kim HJ: Honokiol exerts an anticancer effect in T98G human glioblastoma cells through the induction of apoptosis and the regulation of adhesion molecules. Int J Oncol 41: 1358-1364, 2012.
20. Khan MA, Tania M, Wei C, Mei Z, Fu S, Cheng J, Xu J and Fu J: Thymoquinone inhibits cancer metastasis by downregulating TWIST1 expression to reduce epithelial to mesenchymal transition. Oncotarget 6: 19580-19591, 2015.

21. Livak KJ and Schmittgen TD: Analysis of relative gene expression data using real-time quantitative PCR and the 2(-Delta Delta C(T)) methods. Methods 25: 402-408, 2001

22. Gheldof A and Berx G: Cadherins and epithelial-to-mesenchymal transition. Prog Mol Biol Transl Sci 116: 317-336, 2013.

23. Tania M, Khan MA and Fu J: Epithelial to mesenchymal transition inducing transcription factors and metastatic cancer. Tumour Biol 35: 7335-7342, 2014.

24. McConkey DJ, Choi W, Marquis L, Martin F, Williams MB, Shah J, Svatek R, Das A, Adam L, Kamat A, et al: Role of epithelial-to-mesenchymal transition (EMT) in drug sensitivity and metastasis in bladder cancer. Cancer Metastasis Rev 28 335-344, 2009.

25. Khan MA, Chen HC, Zhang D and Fu J: Twist: A molecular target in cancer therapeutics. Tumour Biol 34: 2497-2506, 2013.

26. Jäger T, Becker M, Eisenhardt A, Tilki D, Tötsch M, Schmid KW Romics I, Rübben H, Ergün S and Szarvas T: The prognostic value of cadherin switch in bladder cancer. Oncol Rep 23: $1125-1132,2010$

27. Guo S, Xu J, Xue R, Liu Y and Yu H: Overexpression of AIB1 correlates inversely with E-cadherin expression in pancreatic adenocarcinoma and may promote lymph node metastasis. Int J Clin Oncol 19: 319-324, 2014

28. Wang M, Zhao F, Li S, Chang AK, Jia Z, Chen Y, Xu F, Pan H and $\mathrm{Wu} \mathrm{H}$ : AIB1 cooperates with ER $\alpha$ to promote epithelial mesenchymal transition in breast cancer through SNAI1 activation. PLoS One 8: e65556, 2013.

29. Qin L, Liu Z, Chen H and Xu J: The steroid receptor coactivator-1 regulates twist expression and promotes breast cancer metastasis. Cancer Res 69: 3819-3827, 2009.

30. Hsu I, Yeh CR, Slavin S, Miyamoto H, Netto GJ, Tsai YC Muyan M, Wu XR, Messing EM, Guancial EA and Yeh S: Estrogen receptor alpha prevents bladder cancer via INPP4B inhibited akt pathway in vitro and in vivo. Oncotarget 5 : 7917-7935, 2014

31. Wang Y, Lonard DM, Yu Y, Chow DC, Palzkill TG and O'Malley BW: Small molecule inhibition of the steroid receptor coactivators, SRC-3 and SRC-1. Mol Endocrinol 25: 2041-2053, 2011.

32. Wang Y, Lonard DM, Yu Y, Chow DC, Palzkill TG, Wang J, Qi R, Matzuk AJ, Song X, Madoux F, et al: Bufalin is a potent small-molecule inhibitor of the steroid receptor coactivators SRC-3 and SRC-1. Cancer Res 74: 1506-1517, 2014.

33. Yan F, Yu Y, Chow DC, Palzkill T, Madoux F, Hodder P, Chase P, Griffin PR, O'Malley BW and Lonard DM: Identification of verrucarin a as a potent and selective steroid receptor coactivator-3 small molecule inhibitor. PLoS One 9: e95243, 2014.

34. Avtanski DB, Nagalingam A, Bonner MY, Arbiser JL, Saxena NK and Sharma D: Honokiol inhibits epithelial-mesenchymal transition in breast cancer cells by targeting signal transducer and activator of transcription 3/Zeb1/E-cadherin axis. Mol Oncol 8 : $565-580,2014$

35. Leeman-Neill RJ, Cai Q, Joyce SC, Thomas SM, Bhola NE, Neill DB, Arbiser JL and Grandis JR: Honokiol inhibits epidermal growth factor receptor signaling and enhances the antitumor effects of epidermal growth factor receptor inhibitors. Clin Cancer Res 16: 2571-2579, 2010.

36. Ahn KS, Sethi G, Shishodia S, Sung B, Arbiser JL and Aggarwal BB: Honokiol potentiates apoptosis, suppresses osteoclastogenesis, and inhibits invasion through modulation of nuclear factor-kappaB activation pathway. Mol Cancer Res 4: 621-633, 2006

37. Liu SH, Lee WJ, Lai DW, Wu SM, Liu CY, Tien HR, Chiu CS, Peng YC, Jan YJ, Chao TH, et al: Honokiol confers immunogenicity by dictating calreticulin exposure, activating ER stress and inhibiting epithelial-to-mesenchymal transition. Mol Oncol 9: 834-849, 2015

38. Joo YN, Eun SY, Park SW, Lee JH, Chang KC and Kim HJ: Honokiol inhibits U87MG human glioblastoma cell invasion through endothelial cells by regulating membrane permeability and the epithelial-mesenchymal transition. Int J Oncol 44 187-194, 2014. 